\title{
Chronic obstructive pulmonary disease and exacerbations: Patient insights from the global Hidden Depths of COPD survey
}

Neil Barnes ${ }^{1 *}$, Peter MA Calverley ${ }^{2}$, Alan Kaplan ${ }^{3}$ and Klaus F Rabe ${ }^{4}$

\begin{abstract}
Background: Although chronic obstructive pulmonary disease (COPD) is a major global health burden there is a lack of patient awareness of disease severity, particularly in relation to exacerbations.

Methods: We conducted a global patient survey using an innovative, internet-based methodology to gain insight into patient perceptions of COPD and exacerbations in a real-world sample typical of today's working-age COPD population.

Results: Two thousand patients with COPD (53\%), chronic bronchitis (52\%) and/or emphysema (22\%) from 14 countries completed an online questionnaire developed by the authors. The Medical Research Council (MRC) breathlessness scale was used to delineate symptom severity. Over three quarters of patients (77\%) had experienced an exacerbation, with 27\% of MRC 1 and 2 patients and 52\% of MRC 3, 4 and 5 patients requiring hospitalization as a result of an exacerbation. While a majority of MRC 1 and 2 patients (51\%) reported being back to normal within a few days of an exacerbation, $23 \%$ of MRC 3, 4 and 5 patients took several weeks to return to normal and $6 \%$ never fully recovered. A high proportion of patients (39\%) took a 'wait and see' approach to exacerbations.

Despite the high prevalence of exacerbations and their negative impact on quality of life, 73\% of MRC 1 and 2 patients and $64 \%$ of MRC 3, 4 and 5 patients felt that they had control of their COPD. However, $77 \%$ of all patients were worried about their long-term health, and 38\% of MRC 1 and 2 patients and 59\% of MRC 3, 4 and 5 patients feared premature death due to COPD.
\end{abstract}

Conclusions: To reduce the adverse effects of COPD on patients' quality of life and address their fears for the future, we need better patient education and improved prevention and treatment of exacerbations.

Keywords: COPD, Exacerbation, Patient-reported, Survey

\section{Background}

Chronic obstructive pulmonary disease (COPD) is a major global health burden in both developed and developing countries. The disease is predicted to become the third leading cause of worldwide disease burden by 2030 [1]. COPD is also the leading respiratory cause of days lost from work [2], and three quarters of COPD patients report difficulty in simple day-to-day activities such as dressing and walking up stairs [3].

\footnotetext{
*Correspondence: neil.barnes@bartshealth.nhs.uk

1 Department of Respiratory Medicine, London Chest Hospital (Barts Health NHS Trust), Bonner Road, London E2 9JX, UK

Full list of author information is available at the end of the article
}

Until recently, the major goal of COPD treatment was the reduction of symptoms. However, with the recognition that exacerbations of COPD are very common, have a major adverse impact on quality of life, and may speed disease progression, guidelines and clinical attention are focusing on reducing future risks, such as the prevention and treatment of exacerbations [4]. In developed countries the hospitalization of COPD patients, caused predominantly by exacerbations, accounts for more than $50 \%$ of direct healthcare costs [5].

Surveys of patients with COPD have found that there is a considerable burden of disease and that patients have a poor knowledge of COPD [6-9]. Furthermore, an international survey of 3,265 COPD patients revealed that

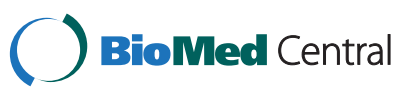


many patients underestimate the severity of their disease [10]. However, these surveys have relied on relatively small sample sizes or have been predominantly focused on Europe and North America. Therefore, we aimed to gain a global insight into patients' perceptions of COPD and, more uniquely, their exacerbations, in a real-world setting using an innovative, internet-based methodology. The survey was designed to identify differences and similarities in perceptions between patients of differing COPD severities, using the Medical Research Council (MRC) breathlessness scale to delineate severity [11].

\section{Methods}

The survey was performed in 14 countries: Australia, Brazil, Canada, China, Denmark, France, Germany, Italy, the Netherlands, Poland, South Korea, Spain, Turkey and the UK. These countries were chosen to provide a wide geographic and economic spread.

An online approach was used to ensure that the methodology was globally consistent while avoiding the need to rely on treatment centres for recruitment and taking into account the difficulty in implementing a telephone survey in countries such as China and Brazil. The survey therefore avoided potential biases within specialist centres or regions as well as biases related to disease severity or treatment. This innovative, internet-based method, commonly used for consumer research, recruited participants from established online general population research panels containing over 18 million members worldwide. The research was implemented by professional market researchers (ICM Research) in accordance with the Legal and Ethical Guidelines issued by the British Healthcare Business Intelligence Association (BHBIA) and was conducted in accordance with codes of conduct regarding anonymity, confidentiality and ethical practice. The survey was therefore exempt from ethics approval under the UK Governance arrangements for research ethics committees.

Based on a self-reported respiratory condition/breathing problem and/or a positive current or former smoking history, 255,710 individuals were invited to participate in the survey between 09 July and 02 September 2010. Information about the survey, which included the length of time for completion of the questionnaire (approximately 17 minutes), was e-mailed to the invitees. Incentives were offered in line with the terms and conditions of the panels, and were often non-monetary, or ranged from the equivalent of $£ 0.20$ to $£ 1$ per minute of survey. Of 255,710 invitees, 75,233 responded and, after providing consent, were screened for eligibility, producing 5,929 respondents who were able to withdraw at any point. A sample size of 2,000 completed questionnaires was used for analysis (Figure 1).
All patients who took part needed to have been diagnosed by a clinician with one or more of the following conditions: COPD, chronic bronchitis or emphysema. Patients also needed to have at least two of the following symptoms: breathlessness on exertion, mucus/sputum/ phlegm production, chronic or troublesome cough, chest pain when walking, regular chest infections (especially in the winter) or leg pain when walking. Disease severity was measured by asking patients to assess themselves according to the criteria of the MRC breathlessness scale (Grades 1-5) [11]. A symptom-based definition of exacerbations was used (a worsening of at least one symptom of COPD lasting for at least 48 hours) [12],

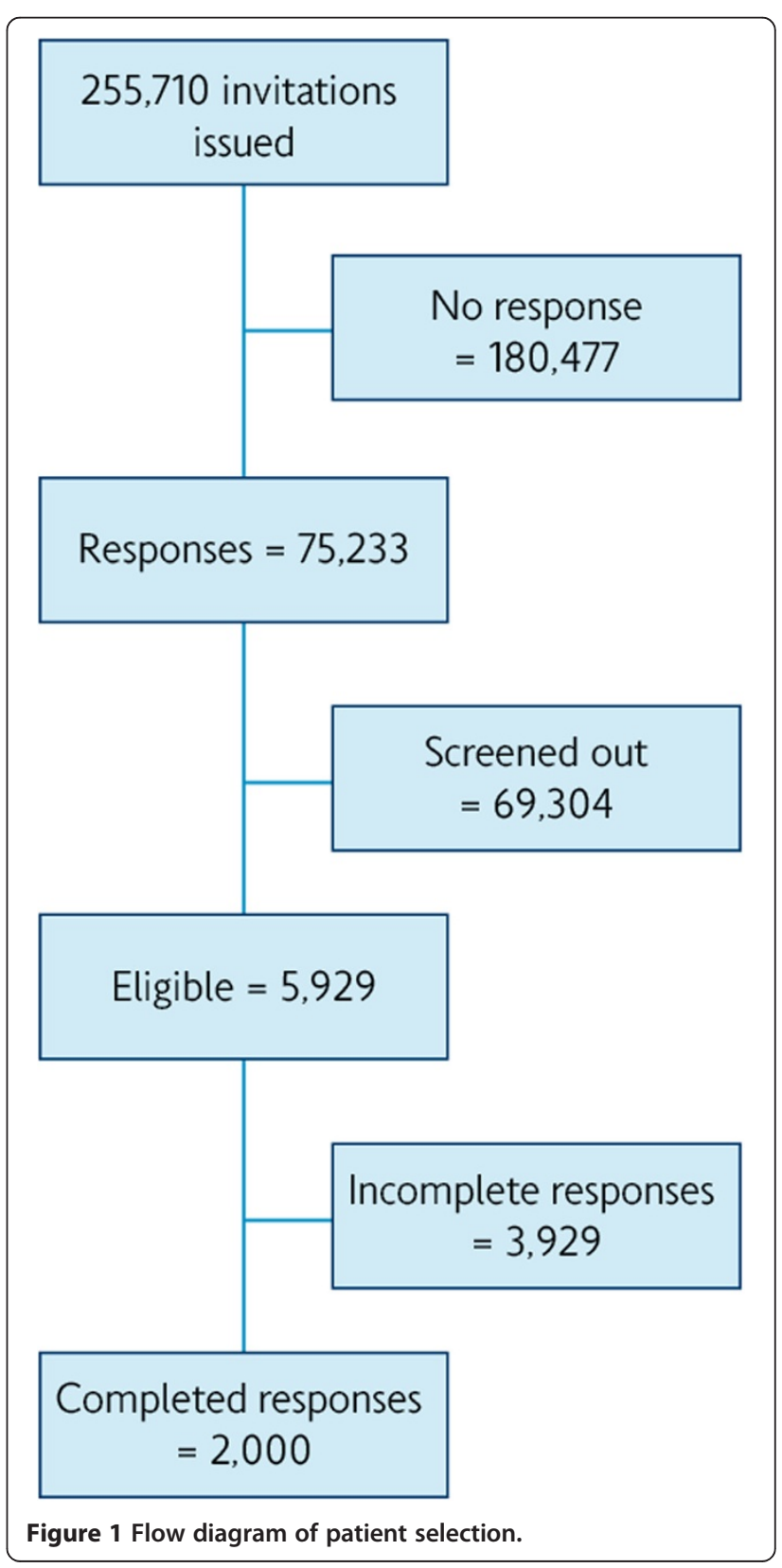


which was outlined for patients each time there was a relevant question.

The survey consisted of a two-part, online, selfcompletion questionnaire that used an adaptive question approach to minimize unnecessary questions and shorten completion times. The questions were developed by the authors using standard measures where appropriate (for example, the MRC breathlessness scale). The questionnaire and the screening approach can be viewed in the online supplement.

The survey was tested by three individuals prior to launch, and was then 'soft-launched' to a limited number of respondents (50-100 per country) so that the data and survey mechanism could be tested for sense/logic, and the average time for completion checked against the original estimate. As some questions were open-ended, completed questionnaires could contain unanswered questions, and checks were only made to ascertain whether text was entered. In addition, respondents were offered a "don't know" answer where applicable to avoid forcing inaccurate responses. Data from incomplete questionnaires were collected but not processed or analysed.

No analytical time stamps were used but all data were logic tested to ensure that respondents did not provide contradictory answers. Quality control questions were included at the beginning and end of the questionnaire. These asked personal information, for example, age at the beginning of the questionnaire and date of birth at the end, and if these answers did not match, the respondent's questionnaire was rejected.

Data were stored in compliance with the UK Data Protection Act (1998) on secure servers that could be accessed only by relevant researchers, and each respondent was issued with a unique Uniform Resource Locator (URL) that could be used once to access the questionnaire. Respondents were not able to review or edit their answers to previous questions.

The current publication was developed in line with the Checklist for Reporting Results of Internet E-Surveys (CHERRIES) [13].

\section{Statistical analysis}

The collected data were processed and tabulated into electronic data tables. Descriptive statistics are presented herein.

\section{Role of the funding source}

The study was sponsored by Nycomed (a Takeda company). A Steering Committee of COPD experts including primary and secondary care physicians designed the survey in conjunction with six representatives of the sponsor. This included the original study design and concept, the plan for the analyses, full access to the data and responsibility for decisions with regard to publication. The research was implemented by professional market researchers (ICM Research).

\section{Results}

The 2,000 completed questionnaires consisted of 150 questionnaires from each country except for Denmark and Turkey, where limited numbers of individuals in consumer research panels meant that only 100 completed questionnaires in each of these countries were gathered. The mean age (standard error [SE]) of the population was $52.99(0.22)$ years, $53 \%$ of patients were current smokers, 1,231 (62\%) patients were classified as MRC breathlessness scale 1 and 2, and 769 (38\%) patients were classified as MRC breathlessness scale 3, 4 and 5 (Table 1). The UK had the highest percentage $(58 \%)$ and Italy the lowest percentage (22\%) of MRC 3, 4 and 5 patients (Table 1). Symptoms such as breathlessness on exertion, fatigue, sputum production and cough were very common (Table 1). Regular chest infections were experienced by $41 \%$ of MRC 1 and 2 patients and $57 \%$ of MRC 3, 4 and 5 patients. The majority of patients $(69 \%)$ thought that their COPD was controlled, yet MRC 1 and 2 patients and MRC 3, 4 and 5 patients reported a mean (SE) of $10(0.27)$ and $18(0.37)$ days per month, respectively, in which COPD negatively affected their life. The majority of patients felt that their doctor took their disease seriously or very seriously, with only a minority (5\% of all patients) feeling that their doctor did not take their condition seriously at all (Table 1).

Patients reported high healthcare utilization in the preceding 12 months of the survey (Figure 2). This included high frequencies of scheduled and unscheduled visits to primary care physicians, specialists and allied healthcare professionals such as physiotherapists (Figure 2). Use of unscheduled healthcare was particularly common among MRC 3, 4 and 5 patients, with a peryear mean (SE) of 1.77 (0.17) unscheduled GP visits, 0.85 (0.13) unscheduled visits to hospital specialists and 0.70 (0.11) unscheduled visits to a nurse. MRC 3, 4 and 5 patients also reported a per-year mean (SE) of 1.06 (0.12) unscheduled visits to the emergency department, with $19 \%$ of these patients reporting two or more visits.

Self-reported comorbidities were generally more common in MRC 3, 4 and 5 patients compared with MRC 1 and 2 patients, and included hypertension (37\%), anxiety (36\%), depression (34\%), leg muscle weakness (30\%), heartburn (29\%), arthritis (28\%), hyperlipidaemia/high cholesterol (22\%), sleep apnoea (23\%) and diabetes (20\%) (Figure 3).

Prescription medication was used by a high percentage of all patients (89\%), with bronchodilators the mainstay of treatment, as per COPD guidelines (Table 2) [4]. Over a quarter $(27 \%)$ of patients had taken steroids, and $43 \%$ 
Table 1 Patient demographics, symptoms and perceptions

\begin{tabular}{lcc}
\hline & $\begin{array}{c}\text { MRC 1 } \\
\text { and 2 }\end{array}$ & $\begin{array}{c}\text { MRC 3, 4 } \\
\text { and 5 }\end{array}$ \\
\hline $\mathbf{N}(\%)$ & $1,231(62 \%)$ & $769(38 \%)$ \\
Male, $\mathbf{n}(\%)$ & $656(53 \%)$ & $392(51 \%)$ \\
Female, $\mathbf{n}(\%)$ & $575(47 \%)$ & $377(49 \%)$ \\
Mean age, years (SE) & $52.03(0.28)$ & $54.54(0.35)$
\end{tabular}

MRC breathlessness scale by country, $\mathrm{n}(\%)^{*}$

Australia
Brazil
Canada
China
Denmark
France
Germany
Italy
The Netherlands
Poland
South Korea
Spain
Turkey
The UK

$\begin{array}{ll}84(56 \%) & 66(44 \%) \\ 106(71 \%) & 44(29 \%) \\ 70(47 \%) & 80(53 \%) \\ 110(73 \%) & 40(27 \%) \\ 50(50 \%) & 50(50 \%) \\ 79(53 \%) & 71(47 \%) \\ 84(56 \%) & 66(44 \%) \\ 113(75 \%) & 37(25 \%) \\ 94(63 \%) & 56(37 \%) \\ 98(65 \%) & 52(35 \%) \\ 101(67 \%) & 49(33 \%) \\ 107(71 \%) & 43(29 \%) \\ 72(72 \%) & 28(28 \%) \\ 63(42 \%) & 87(58 \%)\end{array}$

Have you ever taken a pulmonary function test? $\mathrm{n}(\%)$

Yes

$960(78 \%) \quad 678(88 \%)$

No

Current smoking behaviour

More than 20 cigarettes per day, $\mathrm{n}(\%)$

Up to 20 cigarettes per day, n (\%)

Former smoker, n (\%)

Never smoked, $n$ (\%)

Days negatively affected by COPD in a 30 day month, mean days (SE)

COPD symptoms experienced, $\mathbf{n}(\%)$

Breathlessness on exertion
Fatigue
Mucus/sputum/phlegm production
Chronic/troublesome cough
Regular chest infections especially in winter
Leg pain on walking
Chest pain on walking
Other

How seriously does your doctor take your COPD? n (\%)

Very seriously
Fairly seriously
Not particularly seriously
Not at all seriously

$958(78 \%) \quad 704(92 \%)$

$752(61 \%) \quad 606(79 \%)$

$731(59 \%) \quad 505(66 \%)$

$729(59 \%) \quad 484(63 \%)$

$500(41 \%) \quad 439(57 \%)$

$331(27 \%) \quad 340(44 \%)$

$218(18 \%) \quad 277(36 \%)$

$24(2 \%) \quad 15(2 \%)$

$\begin{array}{cc}297(24 \%) & 331(43 \%) \\ 480(39 \%) & 303(39 \%) \\ 347(28 \%) & 107(14 \%) \\ 51(4 \%) & 11(1 \%)\end{array}$

Table 1 Patient demographics, symptoms and perceptions (Continued)

\begin{tabular}{lcc}
\hline How well do patients think their & & \\
COPD is controlled? $\mathbf{n}(\%)$ & & \\
Not at all well & $47(4 \%)$ & $54(7 \%)$ \\
Not particularly well & $255(21 \%)$ & $204(27 \%)$ \\
Quite well & $718(58 \%)$ & $443(58 \%)$ \\
Very well & $178(14 \%)$ & $51(7 \%)$ \\
\hline
\end{tabular}

$\mathrm{MRC}=$ Medical Research Council breathlessness scale; $\mathrm{SE}=$ standard error; $\mathrm{COPD}=$ chronic obstructive pulmonary disease.

${ }^{*} \mathrm{~N}=150$ for each country except for Denmark and Turkey where $\mathrm{N}=100$.

of patients had used antibiotics. Nearly a quarter (23\%) of MRC 3, 4 and 5 patients had taken oxygen. Patients commonly increased medication use with worsening symptoms (Table 2). Lifestyle choices for managing COPD, such as quitting smoking, exercising and eating more healthily, were also common (Table 2).

Over three quarters (77\%) of all patients had experienced an exacerbation (Table 3). The proportion of patients reporting exacerbations in the preceding year was also high: $62 \%$ and $80 \%$ for MRC 1 and 2 patients and MRC 3, 4 and 5 patients, respectively. A high percentage of patients had had two or more exacerbations in the preceding 12 months (Figure 4). Over a half (53\%) of MRC 3, 4 and 5 patients had experienced an exacerbation that required hospitalization (Table 3). While a majority of MRC 1 and 2 patients (51\%) reported being back to normal within a few days of an exacerbation, $23 \%$ of MRC 3, 4 and 5 patients took several weeks to return to normal and 6\% never fully recovered. A high proportion of patients (39\%) took a 'wait and see' approach to exacerbations (Table 3).

Nearly three quarters $(73 \%)$ of patients contacted their healthcare service during an exacerbation (Figure 5). Other patient reactions to an exacerbation included rest, cutting down on smoking, taking higher doses of medication and taking a medication that would not be part of their usual regimen (Figure 5). Common reasons for seeking healthcare during an exacerbation were an increase in breathlessness, symptoms not improving sufficiently and ineffective medication (Figure 6).

Patients felt that COPD and exacerbations affected their quality of life and the ability to commit to future events (Figure 7). Over three quarters (77\%) of all patients were worried about their long-term health, and $38 \%$ of MRC 1 and 2 patients and 59\% of MRC 3, 4 and 5 patients feared premature death due to COPD (Table 3).

\section{Discussion}

Our survey provides a unique, global perspective of how COPD patients perceive their illness and its impact on their everyday lives, with a focus on patient attitudes 


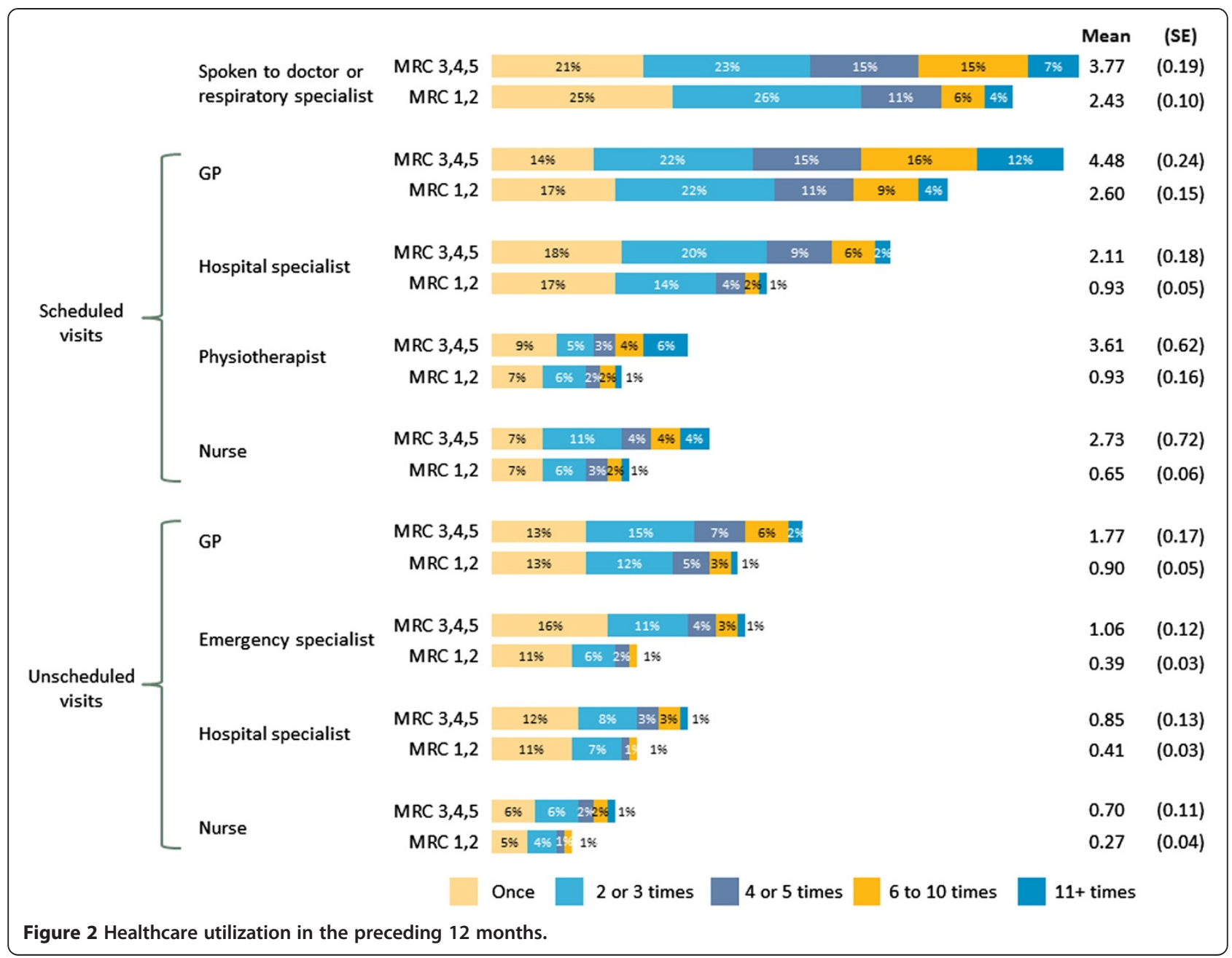

and responses to exacerbations. Recruitment via online research panels aimed to identify 'real-world' COPD patients whose views and experiences of the condition were typical of a wider COPD population. Online recruitment had the advantage of assessing a wide crosssection of the population but had the disadvantage of only assessing individuals with access to the internet who were motivated to respond. Therefore, the data herein may under-represent older individuals and overrepresent more symptomatic individuals who were motivated to respond. However, the age, gender balance, smoking prevalence, symptom reporting, comorbidities and treatment history of the group suggest that respondents were indeed a representative COPD population.

With a mean age of 53 years, the survey cohort was already experiencing regular exacerbations, a considerable impact on daily functioning and high levels of healthcare utilization. These findings support those of other studies that show that the impact of COPD is not restricted to an elderly population $[8,14,15]$. Indeed, an analysis of data from the European Community
Respiratory Health Survey of over 18,000 adults aged 20-44 years concluded that a considerable percentage of the population showed signs of COPD (11.8\% GOLD stage $0,2.5 \%$ GOLD stage 1 and $1.1 \%$ GOLD stages 2 and 3) [15].

The incidence of comorbidities reported here is likely associated with the age and smoking characteristics of the population - over half of patients in our survey were current smokers. Comorbidities were common, and were generally similar to those reported by another survey of patients with COPD [9], the Evaluation of COPD Longitudinally to Identify Predictive Surrogate Endpoints (ECLIPSE) data [16], and the comorbidities of COPD patients in The Health Improvement Network (THIN) database [17]. However, the rates of comorbidities in our survey were generally lower than those reported by other studies $[9,16,17]$. Furthermore, rates of comorbidities were generally higher in MRC 3, 4, and 5 patients compared with MRC 1 and 2 patients in our survey, contrasting with the ECLIPSE study that reported no relationship between comorbidity prevalence and COPD 


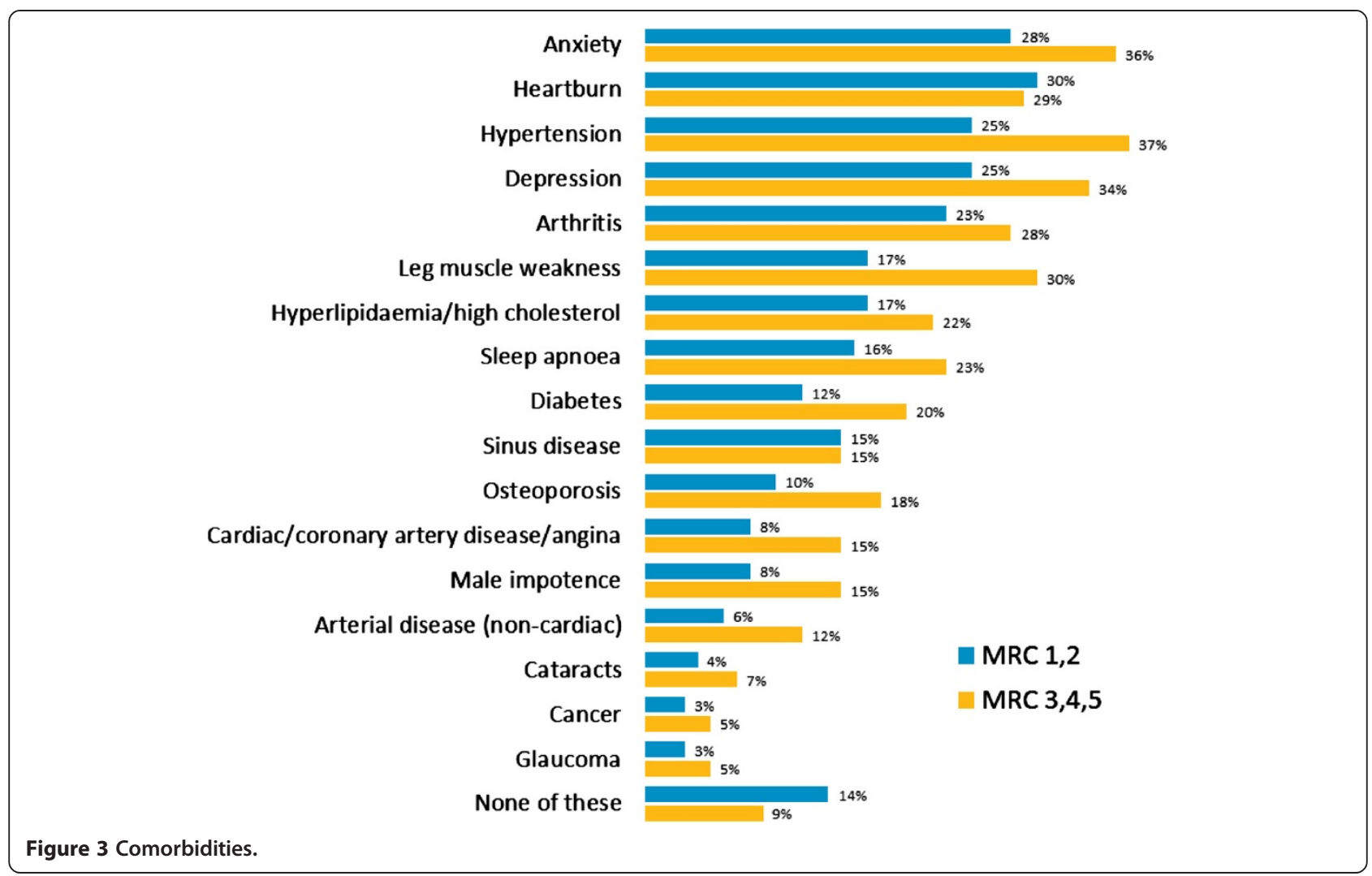

severity. The younger mean age of our survey population compared with the other studies, and inclusion of patients with chronic bronchitis and/or emphysema in our survey, may explain the differing comorbidity observations.

Treatment history was typical of a COPD population, and showed a relatively positive infiltration of guideline messages and an encouraging level of physical management approaches. The COPD Resource Network Needs Assessment Survey reported both patient and physician confusion about COPD treatment choices, and underuse of pulmonary rehabilitation [6]. In our survey, patients reported using physical and breathing exercises, but low rates of pulmonary rehabilitation, suggesting that better access to this treatment approach is still needed.

Patients generally believed that their COPD was well controlled despite the high rate of exacerbations and resulting need to consult healthcare services, rest and increase their medication. This type of mismatch is not unusual, and has been widely reported in studies of both COPD and asthma patients, suggesting low levels of expectation $[6,10,18]$. For example, the Confronting COPD International Survey, the first large international (EU and US) survey on the burden of COPD, reported that over a third of patients with the most severe breathlessness (too breathless to leave the house) described their condition as mild or moderate, as did $60 \%$ of patients characterised as breathless after walking a few minutes on level ground [10]. Similarly, in the COPD Resource Network Needs Assessment Survey, the majority of patients expressed satisfaction with their care despite experiencing significant symptoms and high healthcare utilization [6].

The MRC breathlessness scale proved a useful selfassessment indicator of COPD severity in our survey, with a consistent association between higher MRC scale (3, 4 and 5) and increased prevalence of exacerbations and symptoms, increased prescribed medication use and greater healthcare utilization. In addition, nearly twice as many MRC 3, 4 and 5 patients reported that their doctor took their condition very seriously compared with MRC 1 and 2 patients.

Patient reporting of COPD exacerbations is a relatively reliable measure of true exacerbation frequency, with a good correlation between patient recall of the number of exacerbations and documented occurrence of exacerbations $[19,20]$. Furthermore, the high prevalence of exacerbations reported in our survey is consistent with those in other studies of COPD patient reports [7,20-22]. For example, in the Perception of Exacerbations of Chronic Obstructive Pulmonary Disease (PERCEIVE) survey, $89 \%$ of patients reported at least one episode of 'flareup' of symptoms during the preceding year [7]. Patientreported exacerbation rates are typically higher than 
Table 2 Treatments and lifestyle choices for managing COPD

\begin{tabular}{|c|c|c|}
\hline & $\begin{array}{c}\text { MRC } 1 \text { and } 2 \\
(n=1,231)\end{array}$ & $\begin{array}{c}\text { MRC } 3,4 \text { and } 5 \\
\quad(n=769)\end{array}$ \\
\hline \multicolumn{3}{|c|}{$\begin{array}{l}\text { Treatments and lifestyle choices for managing } \\
\text { COPD, } n(\%)\end{array}$} \\
\hline Long-acting bronchodilators & $710(58 \%)$ & $582(76 \%)$ \\
\hline Short-acting bronchodilators & $390(32 \%)$ & $406(53 \%)$ \\
\hline Antibiotics & $494(40 \%)$ & $358(47 \%)$ \\
\hline Steroids (all types) & $267(22 \%)$ & $273(36 \%)$ \\
\hline Other prescription medication & $179(15 \%)$ & $168(22 \%)$ \\
\hline $\begin{array}{l}\text { Natural remedies and/or } \\
\text { alternative medicine }\end{array}$ & $232(19 \%)$ & $147(19 \%)$ \\
\hline Quit smoking & $509(41 \%)$ & $365(47 \%)$ \\
\hline Cutting down on smoking & $480(39 \%)$ & $286(37 \%)$ \\
\hline Breathing exercise & $405(33 \%)$ & $367(48 \%)$ \\
\hline Eating healthier/better diet & $445(36 \%)$ & $320(42 \%)$ \\
\hline Physical exercise & $455(37 \%)$ & $251(33 \%)$ \\
\hline Oxygen & $119(10 \%)$ & $176(23 \%)$ \\
\hline Pulmonary rehabilitation & $87(7 \%)$ & $136(18 \%)$ \\
\hline \multicolumn{3}{|c|}{$\begin{array}{l}\text { Treatments and lifestyle choices used more by } \\
\text { patients during COPD symptom worsening, } \mathrm{n}(\%)\end{array}$} \\
\hline Long-acting bronchodilators & $854(69 \%)$ & $522(68 \%)$ \\
\hline Short-acting bronchodilators & $339(28 \%)$ & $294(38 \%)$ \\
\hline Antibiotics & $228(19 \%)$ & $179(23 \%)$ \\
\hline Steroids (all types) & $202(16 \%)$ & $168(22 \%)$ \\
\hline Other prescription medication & $118(10 \%)$ & $85(11 \%)$ \\
\hline $\begin{array}{l}\text { Natural remedies and/or } \\
\text { alternative medicine }\end{array}$ & $187(15 \%)$ & 95 (12\%) \\
\hline Quit smoking & $182(15 \%)$ & $104(14 \%)$ \\
\hline Cutting down on smoking & $278(23 \%)$ & $150(20 \%)$ \\
\hline Breathing exercise & $273(22 \%)$ & $205(27 \%)$ \\
\hline Eating healthier/better diet & $203(16 \%)$ & $126(16 \%)$ \\
\hline Physical exercise & $217(18 \%)$ & $113(15 \%)$ \\
\hline Oxygen & $170(14 \%)$ & $133(17 \%)$ \\
\hline Pulmonary rehabilitation & $118(10 \%)$ & $82(11 \%)$ \\
\hline
\end{tabular}

MRC=Medical Research Council breathlessness scale; $C O P D=$ chronic obstructive pulmonary disease.

those reported in clinical trials (as very unstable patients are not recruited into clinical trials, and because the patient definition of an exacerbation may not be the same as that used in clinical trials), and suggest that the 'realworld' experience of COPD patients is different from that of patients in a research setting. The inclusion of approximately twice as many patients with chronic bronchitis compared with patients with emphysema in our survey may contribute to the relatively high prevalence of exacerbations and relative paucity of comorbidities in our survey.
Table 3 Exacerbations and psychosocial impact

\begin{tabular}{|c|c|c|}
\hline & $\begin{array}{c}\text { MRC } 1 \\
\text { and } 2 \\
(n=1,231)\end{array}$ & $\begin{array}{c}\text { MRC 3,4 } \\
\text { and 5 } \\
(n=769)\end{array}$ \\
\hline \multicolumn{3}{|c|}{ Proportion of patients with an exacerbation, $\mathrm{n}(\%)$} \\
\hline Ever & $875(71 \%)$ & $659(86 \%)$ \\
\hline In the last 12 months & $760(62 \%)$ & $617(80 \%)$ \\
\hline $\begin{array}{l}\text { Proportion of people hospitalised by an } \\
\text { exacerbation (baseline: } n=875 \& 659), n(\%)\end{array}$ & $239(27 \%)$ & $342(52 \%)$ \\
\hline \multicolumn{3}{|l|}{$\begin{array}{l}\text { Time taken to return to normal after an } \\
\text { exacerbation (baseline: } n=875 \& 659), n(\%)\end{array}$} \\
\hline Within a few days & $450(51 \%)$ & $266(40 \%)$ \\
\hline Within a week & $255(29 \%)$ & $169(26 \%)$ \\
\hline Within a few weeks & $104(12 \%)$ & $150(23 \%)$ \\
\hline Within a month & $28(3 \%)$ & $18(3 \%)$ \\
\hline Within a few months & $16(2 \%)$ & $14(2 \%)$ \\
\hline Longer & $7(1 \%)$ & $3(0 \%)$ \\
\hline Never & $15(2 \%)$ & $39(6 \%)$ \\
\hline \multicolumn{3}{|l|}{$\begin{array}{l}\text { Patient reaction to the onset of an } \\
\text { exacerbation (baseline: } n=875 \& 659), n(\%)\end{array}$} \\
\hline Take action right away & $493(56 \%)$ & $379(58 \%)$ \\
\hline Wait and see & $345(39 \%)$ & $246(37 \%)$ \\
\hline Do nothing & $37(4 \%)$ & $34(5 \%)$ \\
\hline \multicolumn{3}{|l|}{$\begin{array}{l}\text { Patient concern for long-term health as a } \\
\text { consequence of having COPD, } n(\%)\end{array}$} \\
\hline Not at all worried & $38(3 \%)$ & $16(2 \%)$ \\
\hline Not particularly worried & $112(9 \%)$ & $25(3 \%)$ \\
\hline Neither worried nor unworried & $167(14 \%)$ & $94(12 \%)$ \\
\hline Somewhat worried & $671(55 \%)$ & $358(47 \%)$ \\
\hline Extremely worried & $236(19 \%)$ & $271(35 \%)$ \\
\hline \multicolumn{3}{|c|}{ Patient fear of premature death from COPD, $n(\%)$} \\
\hline Not at all scared & $171(14 \%)$ & $59(8 \%)$ \\
\hline Not particularly scared & $536(44 \%)$ & $230(30 \%)$ \\
\hline Quite scared & $368(30 \%)$ & $319(41 \%)$ \\
\hline Very scared & $101(8 \%)$ & $134(17 \%)$ \\
\hline
\end{tabular}

Fear of premature death from an exacerbation (baseline: $\mathrm{n}=875$ \& 659), $n$ (\%)

\begin{tabular}{lcc} 
Not at all scared & $110(13 \%)$ & $47(7 \%)$ \\
Not particularly scared & $327(37 \%)$ & $176(27 \%)$ \\
Quite scared & $305(35 \%)$ & $267(41 \%)$ \\
Very scared & $104(12 \%)$ & $149(23 \%)$ \\
\hline
\end{tabular}

$\mathrm{MRC}=$ Medical Research Council breathlessness scale; $\mathrm{COPD}=$ chronic obstructive pulmonary disease.

Our survey cohort reported that recovery from exacerbations could be slow or incomplete, especially for MRC 3,4 and 5 patients. Again, this supports data from clinical studies that demonstrated incomplete recovery 35 days after exacerbation in approximately a quarter of patients [12,23]. The high levels of healthcare utilization 


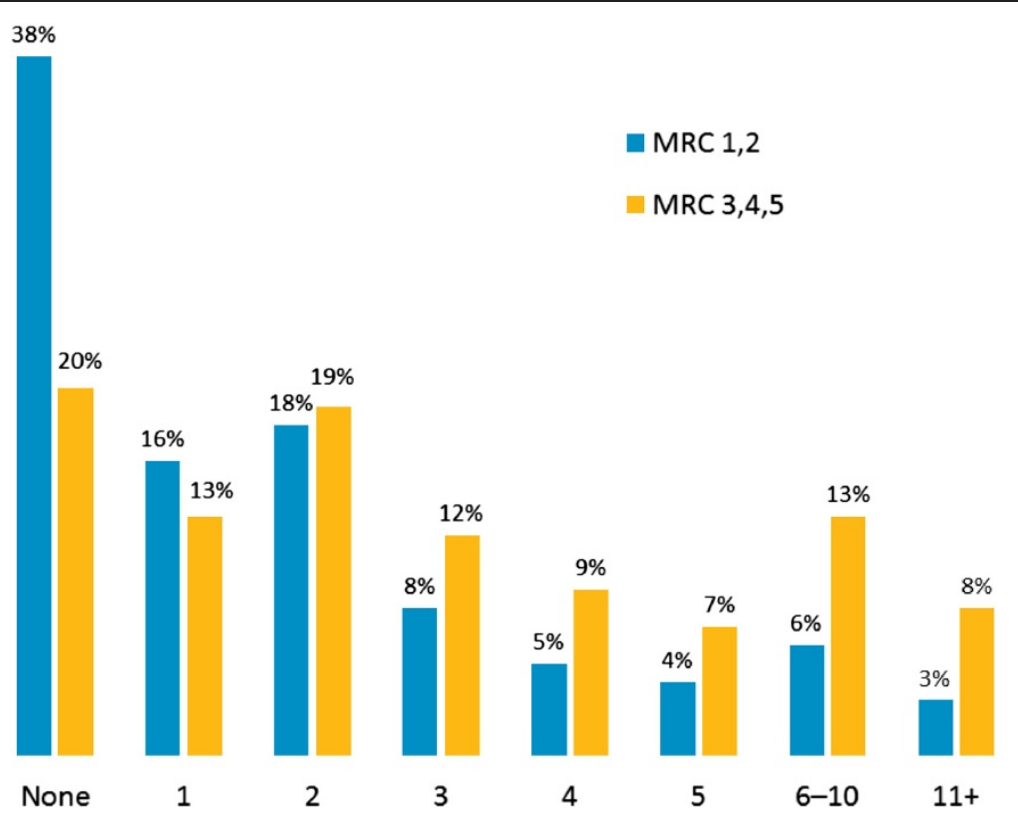

Figure 4 Frequency of exacerbations in the preceding 12 months.

reported in our survey are also similar to those reported by other studies. In PERCEIVE, $89 \%$ of patients who had experienced an exacerbation needed to see their doctor, and $21 \%$ required hospital admission [7]. Exacerbations generated a mean (standard deviation) of 5.1 (4.6) visits to the doctor per patient per year [7].
In a cohort of 128 patients with COPD, earlier treatment of exacerbations was associated with faster recovery (regression coefficient 0.42 days/day delay of treatment; confidence interval, $0.19-0.65 ; \mathrm{p}<0.001$ ), and failure to report exacerbations was associated with an increased risk of emergency hospitalization (Spearman's rank correlation

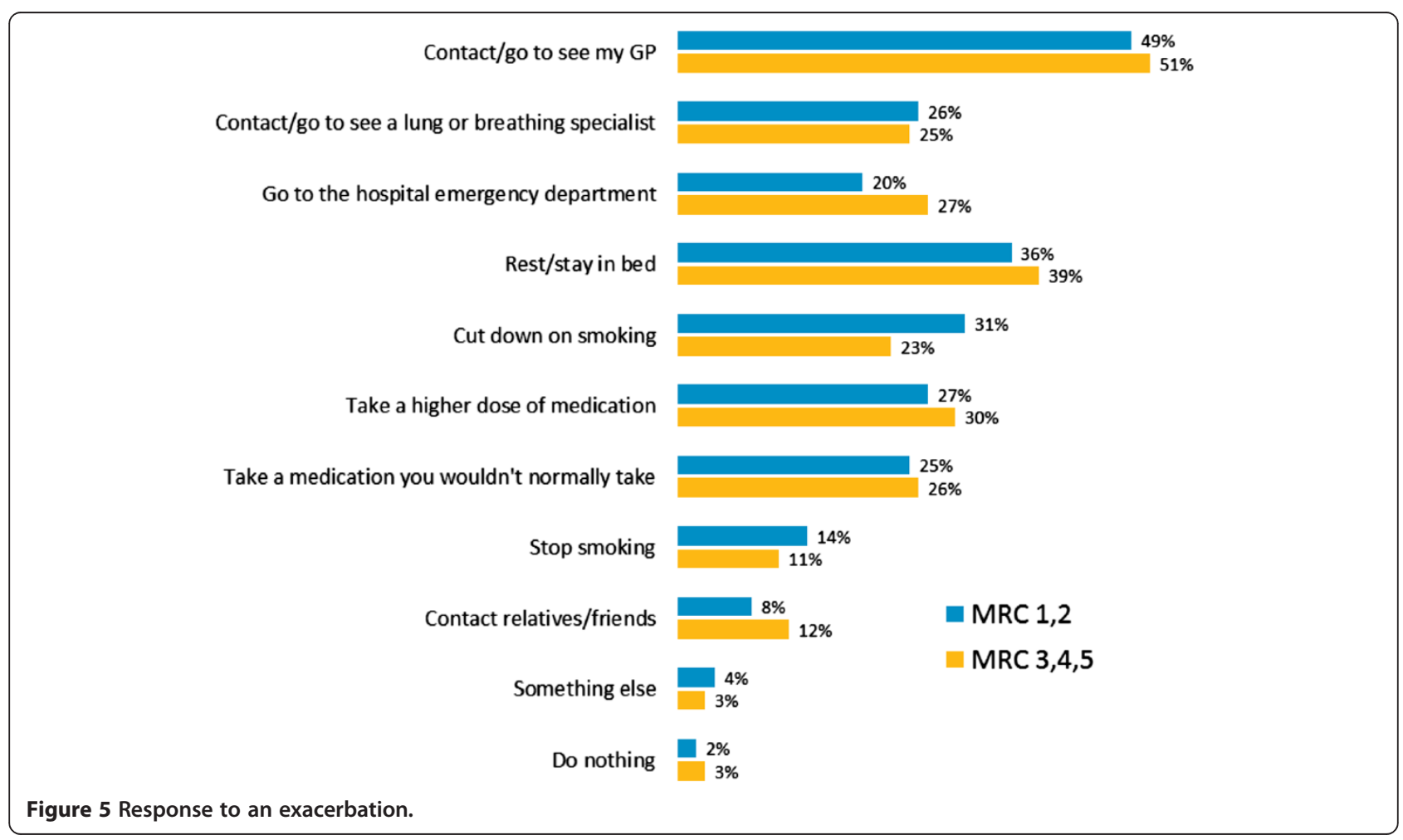




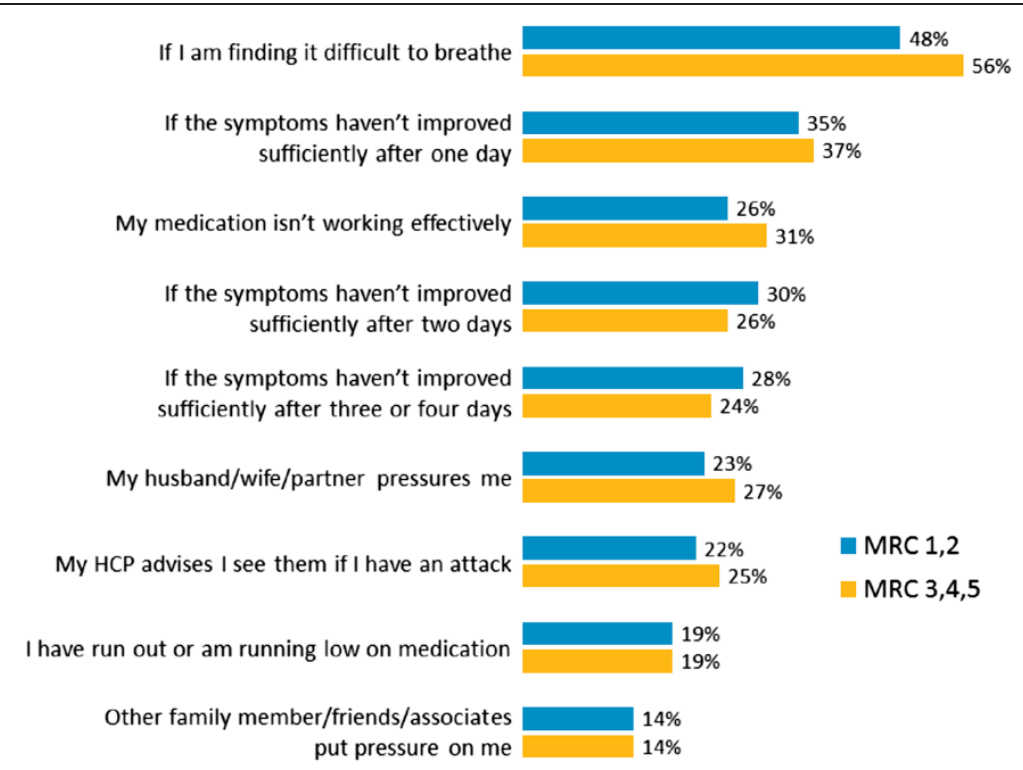

Figure 6 Treatment-seeking triggers during an exacerbation.

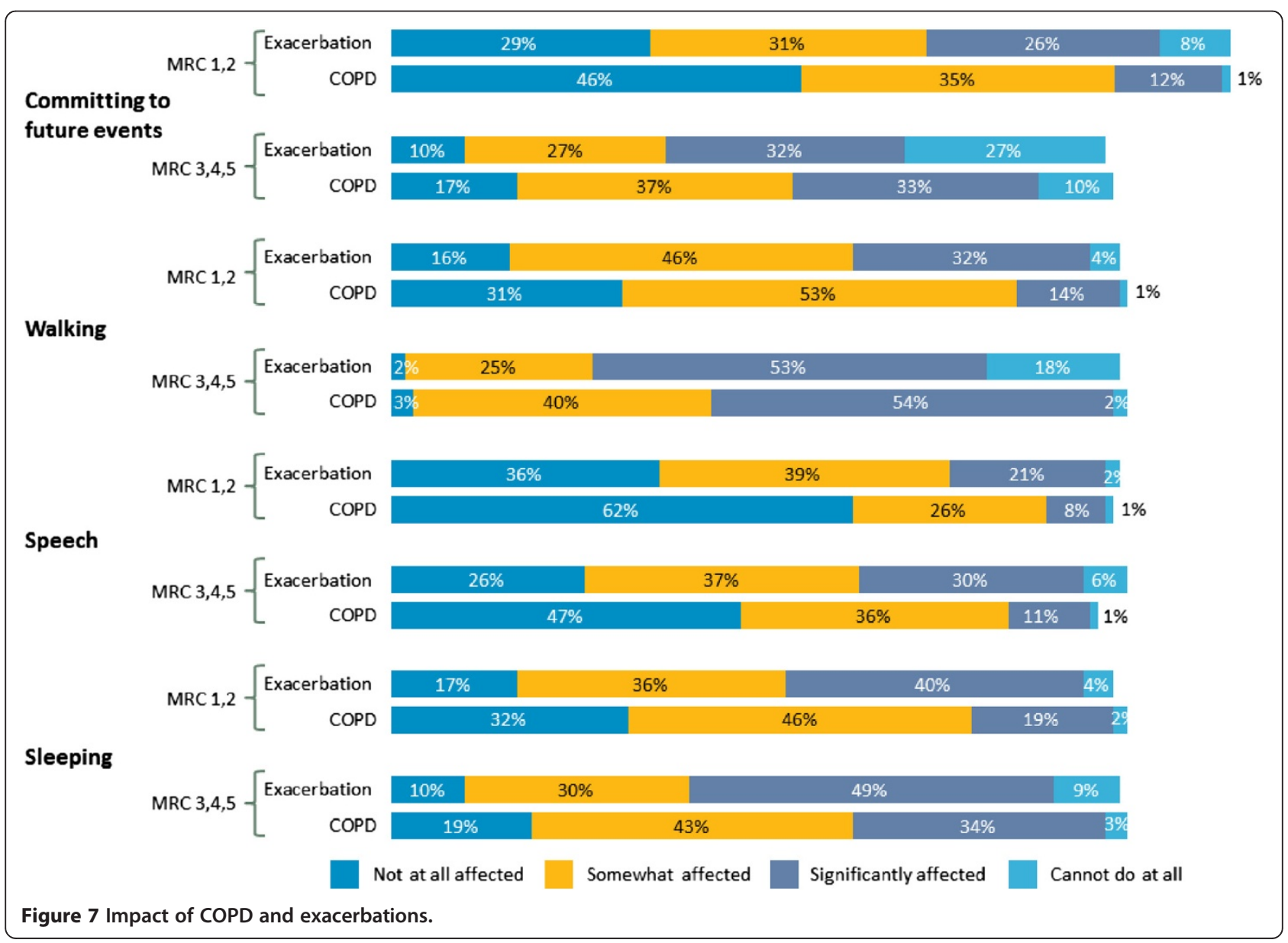


coefficient $=0.21, \mathrm{p}=0.04)$ [24]. As over a third of patients in our survey took a 'wait and see' approach to exacerbations, there is a clear need for better patient education that stresses the importance of a rapid response to symptoms of an exacerbation.

In our survey, exacerbations impacted everyday activities such as sleeping, walking and the ability to commit to future events. For COPD patients of working age, such as those in our cohort, there are additional concerns. For example, a survey of 2,426 COPD patients aged 45-68 years revealed that nearly one in five patients was forced to retire prematurely because of their condition [8]. In addition, patients expressed concern about their ability to maintain their lifestyle and plan for the future [8]. Patients in our survey expressed similar concerns about their future health, as well as fears of premature death arising from COPD, especially as a result of an exacerbation. Palliative care is an important component in the treatment of COPD patients, particularly those with severe disease [25], but access remains poor [26]. Current guidelines recommend that clinicians initiate discussions about end-of-life care with appropriate patients $[4,27]$.

\section{Conclusions}

Our global survey - carried out almost a decade after the Global Initiative for Chronic Obstructive Lung Disease (GOLD) published its first consensus report on the diagnosis, management and prevention of COPD [28] has shown that exacerbations remain a major burden to COPD patients and their families, and put a considerable demand on healthcare services. Furthermore, exacerbations may be more common in a 'real-world' COPD population compared with those in clinical trials.

Our survey has also shown that there is a mismatch between patient perceptions of COPD and the reality of their frequent exacerbations, impaired quality of life and fears for the future. In addition, a high proportion of patients were unaware of the importance of a rapid response to exacerbations, which may be necessary to achieve early and complete resolution of symptoms and recovery of lung function.

By highlighting the fears and concerns of COPD patients, many of whom are of working age with financial and familial responsibilities, the survey draws attention to the need for better patient education regarding the severity of the disease, the importance of prompt treatment of exacerbations, and the treatment and lifestyle options available.

\section{Abbreviations}

CHERRIES: Checklist for Reporting Results of Internet E-Surveys;

COPD: Chronic obstructive pulmonary disease; ECLIPSE: Evaluation of COPD Longitudinally to Identify Predictive Surrogate Endpoints; EU: European Union; GOLD: Global Initiative for Chronic Obstructive Lung Disease: MRC: Medical Research Council; PERCEIVE: Perception of Exacerbations of Chronic Obstructive Pulmonary Disease Survey; SD: Standard deviation;
SE: Standard error; THIN: The Health Improvement Network; UK: United Kingdom; URL: Uniform resource locator; US: United States.

\section{Competing interests}

$\mathrm{N}$ Barnes has received honoraria for giving talks for the following companies: GlaxoSmithKline, AstraZeneca, Chiesi Pharmaceuticals, Boehringer Ingelheim, Teva and Takeda/Nycomed.

PMA Calverley has served on Scientific Advisory Boards of AstraZeneca, Boehringer Ingelheim, GlaxoSmithKline, Novartis and Takeda/Nycomed, and has received research funding from AstraZeneca, Boehringer Ingelheim, GlaxoSmithKline and Takeda/Nycomed.

A Kaplan has served on advisory boards for Boehringer Ingelheim, AstraZeneca, Takeda/Nycomed, Graceway, Novartis, Pfizer and Purdue. He has received honoraria for giving talks for the above companies and GlaxoSmithKline, Merck Frosst, Sanofi and Ortho Janssen.

KF Rabe has received research funding from Altana Pharma, Novartis, AstraZeneca, MSD and Takeda/Nycomed. He has also provided consultation services for AstraZeneca, Chiesi Pharmaceuticals, Novartis, MSD and GlaxoSmithKline. The study was sponsored by Nycomed (a Takeda company). The research was implemented by professional market researchers (ICM Research).

\section{Authors' contributions}

All authors have made substantial intellectual contributions to the conception and design of the study and the analysis and interpretation of the data. All authors have been involved in drafting the manuscript or revising it critically for important intellectual content.

\section{Acknowledgements}

We thank Jenny Bryan and Helen Clark who provided medical writing services on behalf of Takeda Pharmaceuticals/Nycomed. Editorial assistance was provided by Synergy Vision, London on behalf of Takeda

Pharmaceuticals/Nycomed.

\section{Author details}

'Department of Respiratory Medicine, London Chest Hospital (Barts Health NHS Trust), Bonner Road, London E2 9JX, UK. ²Division of Infection and Immunity, Clinical Sciences Centre, University Hospital Aintree, Lower Lane, Liverpool L9 7AL, UK. ${ }^{3}$ Canada and Bedford Park Family Medical Centre, University of Toronto, 17 Bedford Park Avenue, Richmond Hill, Ontario L4C 2N9, Canada. ${ }^{4}$ Department of Medicine, Germany and LungenClinic Grosshansdorf, members of the German Center for Lung Research, University Kiel, D-22927, Grosshansdorf, Germany.

Received: 15 February 2013 Accepted: 5 August 2013

Published: 23 August 2013

\section{References}

1. WHO: World Health Statistics 2008. Available from: http://www.who.int/ whosis/whostat/EN_WHS08_Full.pdf.

2. European Respiratory Society/European Lung Foundation: European Lung White Book. European Respiratory: Society Journals Limited; 2003.

3. Vermeire $P$ : The burden of chronic obstructive pulmonary disease. Respir Med 2002, 96(Suppl C):S3-S10.

4. From the Global Strategy for the Diagnosis, Management and Prevention of COPD, Global Initiative for Chronic Obstructive Lung Disease (GOLD). 2011. Available from: http://www.goldcopd.org/.

5. Wouters EFM: Economic analysis of the Confronting COPD survey: an overview of results. Respir Med 2003, 97(Suppl C):S3-S14.

6. Barr RG, Celli BR, Martinez FJ, Ries AL, Rennard SI, Reilly JJ, Sciurba FC, Thomashaw BM, Wise RA: Physician and patient perceptions in COPD: the COPD Resource Network Needs Assessment Survey. Am J Med 2005, 118(12):1415-1424.

7. Miravitlles M, Anzueto A, Legnani D, Forstmeier L, Fargel M: Patient's perception of exacerbations of COPD-the PERCEIVE study. Respir Med 2007, 101(3):453-460.

8. Fletcher MJ, Upton J, Taylor-Fishwick J, Barnes N, Buist AS, Hutton J, Jenkins C, Jones PW, Salapatas MD, Van der Molen T, Walsh JW, Walker S: COPD uncovered: an international survey on the impact of chronic obstructive pulmonary disease [COPD] on a working age population. BMC Publ Health 2011, 11:612.

9. Barr RG, Celli BR, Mannino DM, Petty T, Rennard SI, Sciurba FC, Stoller JK, Thomashaw BM, Turino GM: Comorbidities, patient knowledge, and 
disease management in a national sample of patients with COPD. Am J Med 2009, 122(4):348-355

10. Rennard S, Decramer M, Calverley PMA, Pride NB, Soriano JB, Vermeire PA, Vestbo J: Impact of COPD in North America and Europe in 2000: subjects' perspective of Confronting COPD International Survey. Eur Respir J 2002, 20(4):799-805.

11. Stenton C: The MRC, breathlessness scale. Occup Med 2008, 58(3):226-227.

12. Seemungal TAR, Donaldson GC, Bhowmik A, Jeffries DJ, Wedzicha JA: Time course and recovery of exacerbations in patients with chronic obstructive pulmonary disease. Am J Respir Crit Care Med 2000, 161:1608-1613.

13. Eysenbach G: Improving the quality of web surveys: the Checklist for Reporting Results of Internet E-Surveys (CHERRIES) Med. Internet Res 2004, 6(3):e34.

14. Buist AS, McBurnie MA, Vollmer WM, Gillespie S, Burney P, Mannino DM, Menezes AM, Sullivan SD, Lee TA, Weiss KB, Jensen RL, Marks GB, Gulsvik A, Nizankowska-Mogilnicka E, on behalf of the BOLD Collaborative Research Group: International variation in the prevalence of COPD (the BOLD study): a population-based prevalence study. Lancet 2007, 370(9589):741-750.

15. De Marco R, Accordini S, Cerveri I, Corsico A, Sunyer J, Neukirch F, Kunzli N, Leynaert B, Janson C, Gislason T, Vermeire P, Svanes C, Anto JM, Burney P, for the European Community Respiratory Health Survey (ECRHS) Study Group: An international survey of chronic obstructive pulmonary disease in young adults according to GOLD stages. Thorax 2004, 59(2):120-125.

16. Agusti A, Calverely PMA, Celli B, Coxson HO, Edwards LD, Lomas DA, MacNee W, Miller BE, Rennard S, Silverman EK, Tal-Singer R, Wouters E, Yates JC, Vestbo J: Characterisation of COPD heterogeneity in the ECLIPSE cohort. Respir Res 2010, 11:122-136.

17. Feary JR, Rodrigues LC, Smith CJ, Hubbard RB, Gibson JE: Prevalence of major comorbidities in subjects with COPD and incidence of myocardial infarction and stroke: a comprehensive analysis using data from primary care. Thorax 2010, 11:956-962.

18. Holgate ST, Price D, Valovirta E: Asthma out of control? A structured review of recent patient surveys. BMC Pulm Med 2006, 6(Suppl 1):S2.

19. Quint JK, Donaldson GC, Hurst JR, Goldring JJ, Seemungal TR, Wedzicha JA: Predictive accuracy of patient reported exacerbation frequency in chronic obstructive pulmonary disease. Eur Respir J 2011, 37(3):501-507.

20. Hurst JR, Donaldson GC, Quint JK, Goldring JJP, Baghai-Ravary R, Wedzicha JA: Temporal clustering of exacerbations in chronic Obstructive pulmonary disease. Am J Resp Crit Care 2009, 179(5):369-374.

21. Kessler R, Ståhl E, Vogelmeier C, Haughney J, Trudeau E, Löfdahl CG, Partridge MR: Patient understanding, detection and experience of COPD exacerbations. Chest 2006, 130(1):133-142.

22. Haughney J, Partridge MR, Vogelmeier C, Larsson T, Kessler R, Ståhl R, Brice R, Löfdahl CG: Exacerbations of COPD: quantifying the patient's perspective using discrete choice modelling. Eur Respir J 2005, 26:623-629.

23. Perera W, Hurst JR, Wilkinson TM, Sapsford RJ, Mullerova H, Donaldson GC, Wedzicha JA: Inflammatory changes, recovery and recurrence at COPD exacerbation. Eur Respir J 2007, 29:527-534.

24. Wilkinson TM, Donaldson GC, Hurst JR, Seemungal TA, Wedzicha JA: Early therapy improves outcomes of exacerbations of chronic obstructive pulmonary disease. Am J Respir Crit Care Med 2004, 169(12):1298-1303.

25. Curtis JR: Palliative and end-of-life care for patients with severe COPD. Eur Respir J 2008, 32(3):796-803.

26. Gardiner C, Gott M, Payne S, Small N, Barnes S, Halpin D, Ruse C, Seamark D: Exploring the care needs of patients with advanced COPD: an overview of the literature. Respir Med 2010, 104(2):159-165.

27. Celli BR, MacNee W, ATS/ERS Task Force: Standards for the diagnosis and treatment of patients with COPD: a summary of the ATS/ERS position paper. Eur Respir J 2004, 23(6):932-946.

28. Pauwels RA, Buist AS, Calverley PM, Jenkins CR, Hurd SS, on behalf of the GOLD Scientific Committee: Global strategy for the diagnosis, management, and prevention of chronic obstructive pulmonary disease. NHLBI/WHO Global Initiative for Chronic Obstructive Lung Disease (GOLD) workshop summary. Am J Respir Crit Care Med 2001, 163(5):1256-1276.

\section{Submit your next manuscript to BioMed Central and take full advantage of:}

- Convenient online submission

- Thorough peer review

- No space constraints or color figure charges

- Immediate publication on acceptance

- Inclusion in PubMed, CAS, Scopus and Google Scholar

- Research which is freely available for redistribution 